\section{IDENTIDAD JUDICIAL INDÍGENA FRENTE A LA JURISDICCIÓN ORDINARIA ACTUAL EN COLOMBIA*}

\section{Omar Antonio Herrán Pinzón** Guillermo García Hernández***}

Fecha de recepción: 12 de Octubre de 2010

Fecha de aceptación: 30 de Noviembre de 2010

Artículo Resultado de Proyecto de Investigación.

\section{Resumen}

E1 Estado Colombiano se enfrenta a una realidad social diversa, multiétnica y pluricultural cada vez más palpable, que demanda no solo un reconocimiento social, sino constitucional, de tal forma que es necesario observar y analizar como en su práctica sociojurídica la jurisdicción especial indígena, en su campo penal, tiene un impacto en la jurisdicción ordinaria penal Colombiana, que habida cuenta les reconoce la Constitución del 91 a las autoridades indígenas su identidad cultural propia, con organización política, administrativa y judicial específicas, cuyas costumbres, normas y procedimientos tienen un impacto, en el ordenamiento Jurídico Nacional.

* Este articulo es un resultado parcial de la investigación denominada "Investigación, Procedimiento y Sanción en la Jurisdicción Indígena Frente a la Jurisdicción Penal actual en Colombia", para optar por el titulo de magister, en Derecho Procesal Penal; forma parte del proyecto de investigación que se adelantada en el grupo de "Derecho Público", CATEGORÍA B- COLCIENCIAS, de la Facultad de Derecho de la Universidad Militar Nueva Granada en la línea de Derecho Penal.

** Abogado de la Universidad Militar Nueva Granada, Maestrante en Derecho Procesal Penal de la misma Universidad.omar.herran@unimilitar.edu.co.

*** Abogado de la Universidad Militar Nueva Granada, Maestrante en Derecho Procesal Penal de la misma Universidad.1auven82@gmail.com.

\author{
Palabras clave \\ Jurisdicción Especial Indígena, Justicia \\ Penal, Pueblos Indígenas, Jurisdicción Penal \\ Ordinaria.
}

\section{IDENTITY INDIGENOUS JUDICIAL COMPARED TO THE REGULAR JURISDICTION CURRENT IN COLOMBIA}

\begin{abstract}
The Colombian government is facing a different social reality, multiethnic and multicultural increasingly evident that demands not only a social recognition, but constitutional, so it is necessary to observe and analyze social and legal practice as a special indigenous jurisdiction in the criminal field, has an impact on the Colombian criminal ordinary jurisdiction, that given them by the Constitution of 91 indigenous authorities their own cultural identity, with political, administrative and specific judicial, whose customs, rules and procedures have an impact in national law.
\end{abstract}

\section{Key words}

Special Indigenous jurisdiction, Criminal Justice, Indigenous Peoples Ordinary Criminal Jurisdiction.

\section{INTRODUCCIÓN}

En la actualidad se generara mucha controversia a la hora de definir a quiénes debía regir y bajo qué parámetros se le debe investigar, procesar y sancionar a los integrantes de las comunidades indígenas con base lo conceptuado en el Artículo 246 de la Constitución Política de $1991^{1}$. A esto se une el hecho de que antes de la Constitución no se contemplaba la situación especial del indígena por lo que la

CONSTITUCIÓN POLÍTICA DE COLOMBIA 1991. 
poca experiencia legislativa resultaba y resulta insuficiente para poder judicializar las conductas de aquellas personas que se encuentran en condiciones especiales.

En consecuencia, el problema que penalmente plantea el juzgamiento de un indígena está en íntima relación con los problemas generales en los órdenes políticos, históricos y económicos orientados al derecho penal del Estado Colombiano que sustenta la puesta en vigencia de este derecho, donde se defiende los derechos más esenciales de una sociedad como la vida, libertad, propiedad, honor, dignidad humana entre otros, permeable a las valoraciones tanto en la jurisdicción indígena como en la ordinaria, el legislador o su análogo en las comunidades indígenas determinan qué acciones serán consideradas falta o delito, se valora por consiguiente en ambos sistemas qué conducta se considera ilícita para que pueda ingresar al sistema penal o jurisdiccional, estas apreciaciones se hacen no desde un sentido de justicia o equidad único sino que se tiene en cuenta la cultura, los intereses de la comunidad o sociedad, por consiguiente, del reconocimiento de la diversidad cultural que se hace a las comunidades indígenas debería ser parte de los principios fundamentales que dan contenido a la política criminal del Estado como base ideológica del sistema penal, situación esta que no ocurre en el sistema penal Colombiano.

Las comunidades indígenas también realizan estas estimaciones y estructuran un modo de resolver sus conflictos ante una agresión a los bienes jurídicos tutelados por ellos dentro de su comunidad; revisar esto es fundamental para la comprensión de la relevancia que este sistema tiene sobre los individuos y de cuanto puede resultar violento la aplicación de un sistema penal ajeno a un individuo que no comparte estas valoraciones ${ }^{2}$.

CORTE CONSTITUCIONAL. Sentencia T- 496/96 M. P. Carlos Gaviria Díaz.
El presente escrito surge como avance de la investigación denominada "investigación, procedimiento y sanción en la jurisdicción indígena frente a la jurisdicción penal actual en Colombia", cuyo problema se concreta en si se restringe el derecho a la autonomía de los pueblos indígenas cuando la jurisdicción ordinaria interviene en el juzgamiento y sanción de los delitos cometidos por los indígenas; dicho interrogante se plantea puesto que el derecho indígena se concibe como conjunto de normas propias, que regulan el desarrollo integral de la vida de estas comunidades ${ }^{3}$. Uno de los rasgos relevantes es la no normativización, esto representa que el derecho indígena no puede ser sometido a un conjunto de normas escritas, porque se apoya imprescindiblemente en la tradición oral, la administración de justicia indígena al sancionar las faltas cometidas por sus integrantes ostenta un sistema de autoridad claramente definida con sanciones para quienes se desvíen de las reglas, de tal forma que el presente texto se centrará en la autonomía en cuanto a investigación, procedimiento y sanción de la jurisdicción indígena de la comunidad Cristianía de Jardín (Antioquia), frente a la jurisdicción ordinaria penal actual en Colombia. si bien es cierto la Jurisdicción Especial Indígena fue reconocida en la Constitución Política de 1991, es necesario determinar el derecho propio de las comunidades indígenas, ya que la forma de reprender las faltas en cada comunidad son diferentes ${ }^{4}$ lo que hace necesario determinar si el sistema Jurídico Penal Nacional y la jurisdicción Especial Indígena interactúan en la aplicación del derecho como norma reguladora de las relaciones sociales, en lo pertinente a la aplicación del derecho penal, respetando la autonomía en la investigación,

3 CORTE CONSTITUCIONAL. Sentencia T- 254/94 M. P. Eduardo Cifuentes Muñoz.

4 CORTE CONSTITUCIONAL. Sentencia C- 139/96 M. P. Carlos Gaviria Díaz. 
procedimiento y sanción de la jurisdicción indígena.

Para solucionar el interrogante planteado se ha utilizado los métodos histórico -lógico en razón a que el trabajo tiene un contenido histórico de carácter jurídico- social que da cuenta de los usos y costumbres que sustenten el sistema judicial consuetudinario de los indígenas; el método hermenéutico, porque se precisa del análisis normativo y jurisprudencial de la temática descrita; de esta manera se podrá precisar la evolución si la hay del derecho indígena y su correlación con el derecho Estatal. Y el método dialéctico, para todos los casos, porque precisa ser abordado desde la casualidad y el efecto, por lo que entraran elementos vinculados a las variables sociales y políticas que determinaron las decisiones en cada momento, ellas pueden ser económicas, culturales o políticas etc. De tal manera que el momento histórico que nos interesa es el actual desde los hechos y antecedentes hasta las implicaciones que dieron paso a una nueva forma o transformación del derecho indígena.

La importancia del tema propuesto en esta investigación radica en que pretende elaborar un texto resultado de la investigación, producto de un análisis hermenéutico y jurídico donde se pueda definir el derecho indígena analizando sanciones claramente definidas, determinando un límite legal que se articule con el sistema Penal Nacional, de tal forma que el derecho consuetudinario y el derecho positivo estatal muestre la incidencia que representa el respeto por la autonomía para la investigación, procedimiento y sanción en la Jurisdicción Especial Indígena frente a la Jurisdicción Ordinaria Penal.

El objetivo fundamental para dar solución a la problemática planteada consiste en determinar si el derecho a la autonomía se afecta cuando interviene la jurisdicción penal ordinaria en la investigación, procedimiento y juzgamiento dentro de la administración de la justicia de los indígenas.

\section{JURISDICCIÓN ESPECIAL INDÍGENA}

Para abordar el tema de la investigación, procedimiento y sanción en la jurisdicción indígena, se hace necesario analizar la jurisdicción nacional penal, junto con la jurisdicción indígena en el marco de la Constitución Política de 1991 y bajo los principios rectores fundamentales que orientan el derecho penal junto con su procedimiento, para así hacer un adecuado análisis de lo preceptuado en el Artículo 246 Constitucional, en donde se le otorga a las autoridades de los pueblos indígenas funciones jurisdiccionales dentro de un espacio territorial determinado, de conformidad con sus propias normas y procedimientos, teniendo en cuenta que el ejercicio jurisdiccional de las comunidades indígenas como de la jurisdicción ordinaria siempre están sometidas a la constitución y a la ley .

La constitución, reconoce y proclama la diversidad cultural, dando paso al reconocimiento de derechos básicos donde la diferencia se valore como un componente heterogéneo ${ }^{6}$, en el respeto de los derechos de autonomía y pluralismo jurídico, en el uso de sus costumbres en la investigación, procedimiento y sanción de las conductas que distorsionan la convivencia armoniosa de los indígenas entre sí, de tal forma que es necesario tener una aproximación a lo que se entiende por justicia tanto en las autoridades indígenas, como en la jurisdicción penal ordinaria.

CONSTITUCIÓN POLÍTICA DE COLOMBIA 1991.

6 BLANCO BLANCO, Jacqueline. "Colombia multicultural Historia del derecho a la Inclusión, informe Final de la investigación". En: Revista Diálogos de Saberes. No 22. Centro de Investigaciones Socio Jurídicas. Universidad Libre. Facultad de Derecho. Enero - Junio de 2005. Bogotá. p. 11. 
La justicia, según los arahuacos por ejemplo, se debe a tres principios filosóficos que sirven de orientación en su concepción de justicia: la misión del hombre en el mundo, las fuerzas vitales del universo y por último las dimensiones del ser humano ${ }^{7}$. Estos tres principios filosóficos se fundamentan en una aceptación de cosmovisiones y parámetros valorativos de la naturaleza y el Universo considerados como bienes naturales ofrecidos por la madre tierra $^{8}$, donde el hombre se considera en dos dimensiones: una dimensión física y otra espiritual; la primera "es el cuerpo fisico, constituido por huesos, carnes y líquidos, a semejanza de la madre tierra (piedra, tierra y agua)",; el segundo corresponde a la energía o pensamiento, esta dimensión debe guardar correspondencia con la parte física, de tal manera que lo que necesita la sociedad son personas sanas de espiritualidad y cuerpo, la importancia de estos principios y la concepción que se tiene de ellos en los Arahuacos tiene su justificación en la prohibición de conductas consideras dentro de esta comunidad como perjudiciales es decir aquellas que van en detrimento tanto de las personas como de la naturaleza, teniendo claro que los perjuicios causados a la naturaleza repercuten a la comunidad, lo que lleva a considerar estas conductas de mayor gravedad, de esta forma hablar de conductas delictivas en el campo de las comunidades indígenas y por otro en la jurisdicción Nacional Penal, es sin lugar a dudas un ejercicio que requiere mas que un estudio objetivo de la conducta ${ }^{10}$, un estudio subjetivo y espiritual de la misma donde se estudie la conducta del sujeto activo en las dos dimensiones del hombre, la parte física y la espiritual, toda vez que suele establecerse;

\footnotetext{
ZALABATA TORRES, Rubiel. Justicia Propia entre los Arhuacos. USAID. Valledupar. 2008.

8 Ibid.

9 Ibid.

10 GUNTHER, Jakobs. Dogmática de derecho penal y la configuración normativa de la sociedad. Thomson. Civitas. Madrid. 2004. p. 123.
}

En occidente suele establecerse una escisión entre los hechos de la naturaleza y los hechos impulsados por el hombre, presentándolos como fenómenos independientes. Una lluvia es un fenómeno natural, así como una granizada; el hurto de un bien es un hecho del hombre, así como el incesto, y no existe ninguna relación entre ellos. Y la consecuencia es que el individuo es responsable de los efectos de sus acciones directas y no hay responsable de los de los hechos naturales. Desde la visión Arhuaca, se diría que esta división corresponde a una observación del plano físico, pues el atentar en consideración el plano espiritual, el cual es por lo demás irrescindible en la visión ancestral, se observa que puede haber conexidad o dependencia entre dichos fenómenos ${ }^{11}$.

Así las cosas las autoridades indígenas comportan una relación jurídica con el Estado; a través de la historia se puede identificar como en la época de la colonia se intentó sancionar aquellos actos o conductas que atentaran contra la corona, cometidos tanto por los españoles como en los indígenas, por lo tanto los castigos por faltas a la moral estaban a cargo de las entidades eclesiásticas mientras que la administración quedaba a disposición de la Real Audiencia ${ }^{12}$, de tal forma que la conducta se estudiaba o analizaba bajo parámetros morales dictados por la religión. Consecuencia de este encargo que se le hacía a la iglesia no se le concedió para tratar el caso de los españoles ya que éstos no necesitaban una educación moral porque efectivamente ya la poseían ${ }^{13}$.

11 ZALABATA TORRES, Rubiel. Justicia Propia entre los Arhuacos. Ob. Cit. p. 14

12 Audiencia y Cancillería Real de Santafé en el Nuevo Reino de Granada. Disponible en: http://www. alcaldiabogota.gov.co/sisjur/normas/Norma1. jsp?i=13661

13 GUZMÁN HARTMANN, Erika. Legislación Penal Indigena desde la colonia hasta 1980: ¿Imputabilidad o Inimputabilidad? Disponible en :_http://elcentro. uniandes.edu.co/cr/antropologia/eguzman/ imputabilidad/imputabilidad.htm 
Charles Taylor es enfático en manifestar que los grupos culturales en cualquier nación deben ser reconocidos toda vez que este reconocimiento es lo que hace que los individuos creen una identidad propia, se reconozcan en una cultura especifica y se desarrollen en ella en forma integral. Es la identidad propia por la que las minorías luchan para que se reconozcan en las instituciones públicas, es decir, que se haga público su reconocimiento junto con la idea de la dignidad de todos teniendo en cuenta que todos son iguales ${ }^{14}$.

De manera que tras las humillaciones y olvido desconsiderado por parte del Estado en cuanto a la cosmovisión de los indígenas se observa como el derecho penal antes de 1991 estaba desarticulado del Derecho Consuetudinario Indígena como se puede observar que en:

"1907 el general Uribe Uribe en erudito discurso que la mejor manera de reducir los salvajes a la civilización era, siguiendo el ejemplo de españoles $y$ portugueses, domesticar los indígenas [...] En nuestra condición de raza conquistadora, ya que arrebatamos el suelo al indio y que cada día vamos estrechándolo para lo más recóndito de las selvas, tenemos obligación - si de veras somos cristianosde arrancarlos a la barbarie en que viven, para traerlos a la comunión de la fe, del trabajo y de la sociedad. De seguro que la providencia no creó al indio para conservarle segregado del movimiento general del progreso humano [...] El 27 de diciembre de 1967, con el sueño de invitarlos a una fiesta, fueron asesinados en el hato la rubiera en Arauca, 18 indígenas cuibas, entre ellas 8 niños. El fallo de los jueces recogió el argumento exculpatorio de los sindicados, al manifestar que no sabia que matar indios era delito. Esta figura jurídica fue denominada "ignorancia invencible" y la práctica de

14 HERRAN PINZÓN, Omar. "Las Minorias étnicas Colombianas en la Constitución política del 91". En: Revista Prolegómenos Derechos y Valores. No 24. Centro de Investigaciones Socio Jurídicas. Universidad Militar Nueva Granada. Facultad de Derecho. Julio - Diciembre de 2009. Bogotá. p. 192. cazar indios que la sustentaba era conocida como "cuibiar"o "guahibiar" [...] ${ }^{15}$.

Este fenómeno hoy en día es de un trasegar importante en la consideración de la dignidad humana ${ }^{16}$ como piedra angular en los dos sistemas "judiciales", de tal forma que la concepción de justicia debe darse mediante un proceso de consenso mínimo que determine los principios de justicia social donde todos los sectores de la sociedad puedan converger, y es a partir de ellos que la instituciones se conciben y se construyen ${ }^{17}$, es el carácter consensual el que puede conferirle estabilidad a un ordenamiento jurídico político ${ }^{18}$, el derecho penal en un Estado multicultural ${ }^{19}$ debe incorporar como presupuesto fundamental de que no se sancionará la diversidad cultural, será tomado en cuenta el derecho consuetudinario, que deben ser respetados en las distintas valoraciones sobre las conductas que provengan de parámetros culturales diversos y preexistentes a la cultura oficial ${ }^{20}$, los jueces deben abandonar el paradigma de un operador judicial que solo toma en cuenta la ley y la constitución en un sentido formalista, desconociendo datos importantes del contexto social en que se desenvuelve las infracciones a la ley penal tanto en la jurisdicción indígena como en la jurisdicción nacional y que reporta cierta incidencia en la sociedad mayoritaria del territorio.

$15 \quad$ Ibíd.

16 CORTE CONSTITUCIONAL. Sentencia C- 370/02 M. P. Eduardo Montealegre Lynett.

17 HERRAN PINZÓN, Omar. "Las Minorias étnicas Colombianas en la Constitución política del 91". $\mathrm{Ob}$ Cit.

18 QUINTANA, Oscar. La filosofia politica y las falacias de la Constitución. Disponible en: www.espaciocritico. com

19 CONSTITUCIÓN POLÍticA DE COLOMBIA 1991. Art. 7.

20 CORTE CONSTITUCIONAL. Sentencia T- 048/ 2002 M. P. Álvaro Tafur Galvis. 
La Corte ha dicho que el juez constitucional y los jueces ordinarios, en cada caso concreto, con el fin de preservar los derechos de los integrantes de las comunidades indígenas y de los terceros vinculados a las mismas, pueden intervenir en asuntos relacionados con dichas comunidades, pero sopesando los límites de su intervención, de manera que se logre restablecer el orden jurídico quebrantado sin resquebrajar el derecho de los pueblos indígenas a su autonomía e independencia.

Lo anterior porque de una intervención de las autoridades ordinarias, sopesada, mesurada y específica, en los asuntos relativos a los pueblos indígenas y a sus integrantes, depende en gran medida que la protección a la diversidad étnica y cultural de la nación colombiana, reconocida en el Artículo $7^{\circ}$ de la Constitución Política, sea una realidad.

Así mismo, esta Corte ha sido consciente de la dificultad que para los jueces de la República conlleva su intervención en los asuntos de competencia de las autoridades indígenas, dada la particular relación existente entre los integrantes de las comunidades indígenas con su entorno cultural del cual dichas autoridades son parte fundamental, y debido a la tendencia generalizada de las personas ajenas a tal entorno a adoptar una actitud paternalista hacía dichas comunidades, basada en que "(...) no son partícipes del mundo de valores prevaleciente en el país y que pudiera comprenderse bajo el rubro genérico de "cultura occidental" 21.

Así las cosas para determinar y analizar de manera ordenada y coordinada hay que tener presente los pronunciamientos de la Corte Constitucional a través de sus distintas sentencias ofrece nuevas concepciones sociopolíticas de las etnias colombianas para reconocerles su identidad étnica, política, social, cultural y religiosa así como su autonomía administrativa

$21 \quad$ Ibíd. y judicial, (sentencias C-027/93, T- 426/92 T - 384/94,T-349/96, T-574/96, C-058/94, C-377/94, C 104/95, C- 394/95; C 139/96). Los pueblos indígenas, calificados hace un siglo como "salvajes" 22 , son considerados por la Constitución actual como comunidades culturales diferentes, tratadas como portadoras de otros valores, con otras metas y otras convicciones, que las tradicionalmente valoradas por la cultura occidental (Sentencia C 139/96); la definición de la nación como multiétnica y pluricultural es el reconocimiento de que los pueblos indígenas existen como pueblos dentro del Estado $\mathrm{Nacional}^{23}$, correspondiéndoles derechos especiales como habitantes originarios, entre los cuales está el de la preservación y defensa de sus territorios, a las comunidades indígenas, se les otorga un status especial que se manifiesta en el ejercicio de facultades normativas y jurisdiccionales dentro de su ámbito territorial de acuerdo con sus valores culturales propios tales como diversidad étnica y cultural ${ }^{24}$, la Corte había considerado que la comunidad indígena ha dejado de ser una realidad fáctica y legal para ser sujeto de derechos fundamentales; es decir, que éstos no sólo se predican de sus miembros individualmente considerados, sino de la comunidad misma que aparece dotada de singularidad propia, la que justamente es el presupuesto del reconocimiento expreso que la Constitución hace a la diversidad étnica y cultural de la Nación Colombiana ${ }^{25}$, concepción de sus sistemas jurídicos propios ${ }^{26}$ (Sentencias, T-349/96; SU-039/97; SU 510/98).

22 GACETA CONSTITUCIONAL. Número 18. Bogotá. Viernes 8 de Marzo de 1991.

23 HERRAN PINZÓN, Omar. "Las Minorias étnicas Colombianas en la Constitución política del 91". Ob Cit. p. 205.

24 CORTE CONSTITUCIONAL. Sentencia T-349/96 M.P. Carlos Gaviria Díaz.

25 CORTE CONSTITUCIONAL. Sentencia SU-039/97 M.P. Antonio Barrera Carbonell.

26 CORTE CONSTITUCIONAL. Sentencia SU-510/98 M.P. Eduardo Cifuentes Muñoz. 


\section{GARANTÍAS DE LA JURISDICCIÓN ESPECIAL INDÍGENA}

\subsection{Debido Proceso}

El derecho fundamental al debido proceso constituye un límite jurídico-material de la jurisdicción indígena que ejerce, sus autoridades que realizan según "sus propias normas y procedimientos, siempre y cuando no sean contrarios a la Constitución y a la ley"27. Cualquiera sea el contenido de las disposiciones jurídicas internas de las comunidades indígenas, estás deben respetar los derechos y principios contenidos en el núcleo esencial del derecho consagrado en el Artículo 29 de la Constitución Política ${ }^{28}$. Un límite constitucional explícito al ejercicio de la potestad punitiva por parte de las autoridades de los pueblos indígenas lo constituye la prohibición de imponer penas de prisión perpetua ${ }^{29}$.

\subsection{Legalidad e Individualidad de la Pena o Sanción}

Las restricciones a la autonomía de las comunidades indígenas en lo que hace a la determinación de sus instituciones jurídicas y sus formas de juzgamiento estarían justificadas porque se trata de medidas necesarias para proteger intereses de superior jerarquía, que en este caso serían el derecho a la vida, la prohibición de la esclavitud y la tortura y la legalidad de los procedimientos, los delitos y las penas ${ }^{30}$, el reducir el principio de legalidad a una exigencia de previsibilidad no implica abrir el paso a la arbitrariedad absoluta, ya que

27 CONSTITUCIÓN POLÍTICA DE COLOMBIA 1991. Art. 246.

28 CORTE CONSTITUCIONAL. Sentencia T-254/94 M. P Eduardo Cifuentes Muñoz.

$29 \quad$ Ibíd.

30 CORTE CONSTITUCIONAL. Sentencia T- 349/96 M.P. Carlos Gaviria Díaz. las autoridades están obligadas necesariamente a actuar conforme lo han hecho en el pasado, con fundamento en las tradiciones que sirven de sustento a la cohesión social. "Por otra parte, no puede extenderse este requerimiento hasta volver completamente estáticas las normas tradicionales, en tanto que toda cultura es esencialmente dinámica, así el peso de la tradición sea muy fuerte" 31.

\subsection{Competencia de la Jurisdicción Especial Indígena}

Las autoridades indígenas conocen de asuntos civiles, penales ${ }^{32}$ en los casos en que un delito se cometiera por fuera del resguardo indígena, la Corte Constitucional ha manifestado que para tener derecho a ser procesado y juzgado por la jurisdicción indígena se debe tener en cuenta la conciencia étnica del sujeto y el grado de asimilación de la cultura a la que pertenece, para entrar a determinar el caso en concreto si el indígena sea juzgado y sancionado con el ordenamiento jurídico nacional o si por el contrario debe ser devuelto a su comunidad para que sea juzgado por sus autoridades de acuerdo con sus normas y costumbres ${ }^{33}$.

¿Qué sucede cuando durante el curso del proceso se propone o está pendiente de dirimir un conflicto positivo de competencia entre la jurisdicción especial indígena y el sistema judicial nacional, el juez ordinario decide, por su cuenta, ignorar la probable presencia del fuero indígena o dirime en su favor el conflicto, continúa conociendo del proceso y profiere sentencia condenatoria en contra del miembro de la comunidad indígena? Este es un común denominador de los dos procesos de la referencia. Así pues, de este suceso se deducen, al menos, estas consecuencias: 1) El juez penal ordinario ha incumplido el deber de remitir el

$31 \quad$ Ibíd.

32 CORTE CONSTITUCIONAL. Sentencia T606/2001 M. P. Marco Gerardo Monroy Cabra.

33 CORTE CONSTITUCIONAL. Sentencia T728/2002 M.P. Jaime Córdoba Triviño. 
expediente a la autoridad facultada para dirimir el conflicto de competencia entre distintas jurisdicciones, la cual ya no podrá ejercer su función frente a procesos ya terminados con sentencia condenatoria o absolutoria; 2) Es factible que el indígena deba purgar una condena impuesta por autoridad no competente para fijarla; 3) Es factible la vulneración del derecho fundamental al debido proceso que asiste al indígena de ser juzgado conforme a leyes preexistentes al acto que se imputa, ante juez o tribunal competente y con observancia de la plenitud de las formas propias de cada juicio (C.P., Art. 29); y 4) Es factible la vulneración del derecho fundamental de la autonomía de las comunidades indígenas y de la jurisdicción especial indígena. Así pues, este asunto trasciende de un debate de carácter procesal al escenario de la protección de derechos fundamentales al debido proceso, legalidad, juez natural, las formas propias de cada juicio y el derecho comunitario de la autonomía de las comunidades indígenas.

Por consiguiente, el reconocimiento a la diversidad étnica y cultural que se deriva del Artículo 246 de la Constitución representa la existencia misma de las comunidades indígenas, y por consiguiente el mismo Artículo les permite gozar de un fuero, así como el correlativo derecho colectivo de la comunidad a juzgar a sus miembros. Así, la noción de fuero indígena comporta dos elementos: i) uno personal el miembro de la comunidad indígena ha de ser juzgado de acuerdo a sus usos y costumbres; ii) geográfico, cada comunidad puede juzgar los hechos que ocurran en su territorio, de acuerdo a sus propias normas; estos criterios son los que determinan la competencia de Jurisdicción Indígena $^{34}$; así las cosas, los límites de la jurisdicción especial indígena en el campo penal se refieren a la definición de la falta a través de su derecho consuetudinario tradicional, el

3 CORTE CONSTITUCIONAL. Sentencia T-009/ 2007 M. P. Manuel José Cepeda Espinosa. procedimiento seguido y la sanción impuesta teniendo en cuenta la tensión que surge entre la diversidad étnica respetando lo conceptuado en el Artículo 246 de la Constitución Política de 1991 y jurisdicción penal nacional.

\section{COORDINACIÓN JUDICIAL DE LA JURISDICCIÓN ESPECIAL INDÍGENA}

Ahora bien, el Artículo 246 Constitucional, es el pilar fundamental donde se desarrolla el derecho a la integridad étnica y cultural de los indígenas la relación de los pueblos indígenas con el Estado en lo jurídico más específicamente en el campo penal. Se puede tomar como referente la Ley 89 de 1890, donde se estipula que la normatividad nacional no se aplicaría a los pueblos indígenas en sus resguardos ${ }^{35}$, y por lo tanto es necesario tener en cuenta que la justicia para ellos parte de la integralidad de sus prácticas espirituales, cosmovisionales y costumbres sociales, pero esto no implica que su derecho consuetudinario avance hacia una relación jurídica con el ordenamiento jurídico nacional.

"Hoy nuestra comunicad se hace realidad un sueño, en donde se hará entre todos para un consenso y búsqueda de una convivencia y tolerancia, donde prime la autonomía del gobierno propio, con una ley propia, usos y costumbres, que todo esto se hará un avance histórico para Embera- Chami y los dema pueblos indígenas y una nueva relación con capurías (no indígenas)

Vamos a construir, desde nuestra identidad, una jurisdicción especial bajo la participación de todos, buscando el fortalecimiento el consenso de convivencia pacifica, garantizando los derechos y deberes de las personas ${ }^{136}$.

\footnotetext{
35 Ley 89 de 1980.

36 RESGUARDO INDÍGENA EMBERA - CHAMI DE CRISTIANÍA (KAMATA RUA). La Constituyente Embera y la Jurisdicción Indígena. Jardin, Antioquia. 2001. p. 4.
} 
La Jurisdicción Especial Indígena se torna como un espacio de encuentro de distintas concepciones y sistemas jurídicos que proponen "alternativas en la forma de administrar justicia por parte del sistema judicial nacional" 37 , de tal forma que comunidades como la Embera - Chami resguardo de Cañamomo Lomaprieta trabajan en la construcción de un soporte legal para el manejo de conflicto entre comuneros; además de la aplicación de justicia propia ${ }^{38}$, los Pueblos y Comunidades Indígenas y sus integrantes necesitan gozar de la seguridad jurídica como máxima expresión de su desarrollo integral, que las autoridades de la administración de justicia, conozcan y se integren a la legislación en materia indígena.

En este sentido, la construcción e implementación del manual de convivencia comunitaria, obedece a la necesidad que existe al interior del territorio ancestral de ordenar y consolidar la normatividad interna que regula la vida y los espacios de convivencia colectiva, en concordancia con las políticas organizativas, para que se constituya en el soporte normativo básico que opera desde las organizaciones comunitarias de base como lo son los cabildos y grupos de apoyo, hasta la estructura encargada de administrar Justicia Propia, para lograr así cumplir con la misión primordial de mantener la armonía comunitaria, la defensa integral del territorio y la consolidación de la Autoridad tradicional y la Autonomía.

Así las cosas lo que se pretende con la articulación del sistema judicial indígena y el nacional es la convivencia en sociedad que se reclama dentro del consenso ciudadano, una convivencia satisfactoria donde reine lo autóctono y se mantenga el uso de costumbres es cada vez más conflictivo en la jurisdicción ordinaria,

37 TRAMA Y URDIMBRE. Consecuencias y disonancias entre la Justicia de los Pueblos Indígenas y el Sistema Judicial Colombiano. USAID. Valledupar. p. 85.

$38 \quad$ Ibíd. pues esta se traslapa en ciertos momentos con la jurisdicción indígena, ya que es sensible en concebir sus derechos como irrevocables para la aplicación de cualquier procedimiento en el que se halle inmerso una persona de su comunidad desarrollando el papel de procesado o castigado dentro del territorio concebido por el Estado como nacional y concebidos por estos como suyo, y que justifica la concepción de gobierno propio con la misión de mantenerlo puro y apartado de nuevas costumbres que atenten con su autonomía y respeto por la diversidad étnica y cultural ${ }^{39}$.

Los pueblos indígenas de América Latina y el Caribe se prepararon para encontrarsen en la Primera Cumbre Continental de Comunicadoras y Comunicadores Indígenas del 8 al 12 de noviembre de 2010. Actividad que se dió lugar en el Territorio de Convivencia, Diálogo y Negociación, Resguardo Indígena de La María, Piendamó, ubicado en la región suroccidente de Colombia. (...) ¿Por qué Colombia y cuál es propósito de esta cumbre?. La razón del porque se eligió el Cauca y específicamente el sector de La María Piendamó, se debió al avance sustancial en materia de comunicación indígena mostrado en la región. Además, era una forma de reconocer, por parte de los hermanos indígenas del continente, al Territorio de Diálogo y Negociación de La María Piendamó, y a la vez dar una muestra de solidaridad con los pueblos indígenas de Colombia que sufren la constante violación de sus derechos en su permanente lucha por la defensa de sus territorios, su identidad y su cultura ${ }^{40}$.

39 TASCÓN GONZÁLEZ, Guillermo Antonio. Politica Organizativa de los Pueblos Indigenas de Antioquia. Volver a Recorrer el Camino. Disponible en: http://www.oia. org.co/elementos/nuestra-politica/POL_TICA_ ORGANIZATIVA_OIA_doc.

40 Del 8 al 12 de noviembre de 2010 está agendada la Cumbre Continental de Comunicación Indígena del Abya Yala. Disponible en: http://www.clacpi. org $/ ? \mathrm{p}=443$ 
En desarrollo del Artículo 256 Constitucional la comunidad de Cristianía de Jardín han hecho uso de su derecho a la autonomía administrativa y judicial, desarrollado autoridades judiciales en su marco de represión, buscando una continua construcción y evolución de la constituyente de Cristianía solicitando a los entes estatales respaldo jurídico y moral, con el fin de alcanzar el compromiso con la jurisdicción especial indígena, y tal vez generar un criterio orientador para el operador judicial y para el gobierno nacional a la hora de legislar sobre la coordinación de esta jurisdicción con el sistema nacional judicial.

Sólo a través de una legislación clara y unos parámetros comunes a cada pueblo sobre las faltas y sanciones penales o simbólicas para los agresores, podremos prevenir e intervenir esta modalidad de violencia social. Es de anotar que cada uno de nuestros pueblos deberá tipificar los delitos de violencia intrafamiliar (y por ende de violencia de género) y las sanciones a dichas conductas.

"Cuando asi se requiera, de igual manera se remitirán a la justicia ordinaria los casos de violencia doméstica a los cuales no podamos dar respuesta desde nuestra jurisdicción, ya que reconocemos que la dignidad humana está por encima de cualquiera de nuestras cosmogonías y sistemas judiciales ${ }^{" 4 t}$.

Colombia es un Estado Social de Derecho, lo cual implica una nueva idea de aplicación de la justicia. El pensamiento del constituyente de 1991 concibió una actividad jurisdiccional eficaz, confiable y transparente a cargo de administradores de justicia de las diferentes jurisdicciones comprometidos en proteger y garantizar a la persona los derechos sustanciales y las libertades consagradas en la Constitución Política y en la Ley, con el objeto de alcanzar la convivencia social; de esta forma, las autoridades legitimas indígenas y sus organizaciones

Ibid. representativas, existente como demostración del pluralismo jurídico dentro del ordenamiento jurídico Colombiano. La constituyente Embera de 1998 pretendió la organización social orientada a la búsqueda de soluciones de conflictos enmarcados en 5 categorías como fueron: Familia, territorio, Medio Ambiente, Jaibanismo, Maleficio, Gobierno, administración, Control Social y Faltas.

“(...) El demandante es indigena, perteneciente al Resguardo de Cristianía. Fue condenado por el Consejo de Conciliación y Justicia Indígena a una pena inicial de 15 años de prisión, pero, en decisión de la misma jurisdicción, le fue modificada la pena a 12 años. Posteriormente, en cumplimiento de un fallo de tutela concedido a favor del actor, se readecuó la condena a 9 años. Esta era la pena al momento de impetrar la tutela.

Considera el demandante que, tanto el Consejo como el Director del establecimiento carcelario en donde se encuentra recluido, le violan el derecho fundamental al debido proceso (art. 29), por no proceder al traslado al lugar que, por su condición de indígena le corresponde. Traslado que, según el actor, se ordenó por el Director General del Inpec y que el Director de la Cárcel de Andes se ha negado a cumplir"'s2.

E1 Resguardo Indígena Embera-Chamí de Cristianía, de Jardín, del Departamento de Antioquia, es considerado, como uno de los que más ha avanzado en plasmar sus costumbres y la manera de resolver sus conflictos de forma escrita, al punto de que cuenta con un documento denominado "Constituyente Embera", en el que asuntos puntuales de la justicia propia han sido examinados y expresados en forma escrita en este documento ${ }^{43}$, en efecto: aspectos como la competencia de la jurisdicción, los delitos, las penas y la forma de purgarlas,

\footnotetext{
42 CORTE CONSTITUCIONAL. Sentencia T- 239/ 2002 M.P. Alfredo Beltrán Sierra.

43 Ibíd.
} 
entre otros, están claramente señalados en este documento ${ }^{44}$.

Allí se establece la competencia de la justicia Kapuria $^{45}$ y los consensos con el cabildo Embera, para conocer de hechos delictivos ocurridos en territorio indígena, si los implicados son indígenas. Se expresa que esta competencia desplaza a la justicia ordinaria, de acuerdo con lo señalado en la Constitución en su Artículo 246 y las sentencias T-254 de 1994 y T-349 de 1996 de la Corte Constitucional, ahora bien la clasificación de las faltas y su gravedad están determinados de la siguiente forma ${ }^{46}$ :

\section{Errores o faltas leves}

2. Faltas medianas

\section{Faltas graves}

La clasificación de las faltas tiene como fin determinar si es posible o no la conciliación, determinar la instancia que debe resolver el caso y la posibilidad de remisión a la justicia ordinaria, la necesidad de llevar el conflicto a consideración de la asamblea comunitaria ${ }^{47}$; por lo tanto, los casos leves son investigados y resueltos por la Consejería de Control Social del Cabildo por el vicegobernador, que fundamentalmente ayuda a resolver los problemas por la vía de la conciliación y el seguimiento de los acuerdos establecidos entre las partes ${ }^{48}$. Los otros problemas, excepto los graves, serían de competencia del Consejo de Conciliación y Justicia, los casos graves serían llevados a la

44 VAlENCIA G., María del Pilar. Justicia embera, identidad y cambio cultural. Reflexiones en torno a una experiencia. Pág. 122. Disponible en: http://ilsa. org.co:81/biblioteca/dwnlds/od/elotrdr026-27/ elotrdr026-27-05.pdf

45 Kapuria es la palabra que utiliza la comunidad de cristianía de jardín a los no indígenas.

46 VAlENCIA G., María del Pilar. Justicia embera, identidad y cambio cultural. Reflexiones en torno a una experiencia. Ob. Cit. p. 122.

47 Ibíd. p. 123

48 Ibíd.
Asamblea de la comunidad, para casos como el homicidio, violación sexual o lesiones personales graves la resolución del conflicto no puede reducirse a la conciliación ${ }^{49}$ ésta existe debe simultáneamente aplicarse una sanción o pena que puede ser por el momento privación de la libertad. De acuerdo con los antecedentes de la persona y la capacidad locativa del cabildo los sancionados podrán enviarse a las cárceles kapuría ${ }^{50}$.

"Para tomar sus decisiones el Consejo [Consejo de conciliación y justicia] debe valorar los hechos, tener en cuenta los antecedentes, llamar a los testigos y escuchar a los implicados, y aplicar justicia de acuerdo con la equidad. El Consejo y el Cabildo, cuando lo consideren necesario, promoverán la discusión de un reglamento de faltas y sanciones, que debe ser aprobado en la Asamblea Nacional.

Antes de imponer sanciones, el Consejo debe procurar que haya una reconciliación entre las partes $y$ sus familias, llegando a unos compromisos y a unas condiciones de cumplimiento. Si la falta que se concilia es motivo para sanción de cárcel, el responsable debe permanecer detenido hasta que cumpla sus compromisos. En caso de incumplimiento se aplica la sanción que corresponda.

Las sanciones pueden ser multas, calabozo, trabajo comunitario, cárcel u otras que considere convenientes el Consejo" ${ }^{\prime \prime}$.

Es importante como esta comunidad hace uso de los mecanismos alternativos de la solución de conflictos de una forma más sencilla y con un significativo restaurativo en sus comunidades estos mecanismos en la jurisdicción nacional tiene un significado y fin similar:

“(...) de otra parte, a los funcionarios judiciales (fiscal y juez), compete establecer que los intervinientes del programa (víctima y victimario), lleguen

$49 \quad$ Ibíd. p. 124.

50 CORTE CONSTITUCIONAL. Sentencia T- 239/ 2002 M. P. Alfredo Beltrán Sierra.

$51 \quad$ Ibíd. 
a involucrarse al proceso restaurativo, confianza, libre voluntad y conciencia libre de cualquier modalidad de coacción con pleno conocimiento de lo que significa la mediación o la conciliación al cual se acogen y sin que medie en su determinación las presiones indebidas" ${ }^{\prime 2}$.

Cabe anotar que esta comunidad tiene como uso o costumbre lo que se persigue en la jurisdicción penal nacional; con los mecanismos alternativos de solución de conflictos, "la justicia restaurativa propone la humanización del proceso penal, mediante una opción preferencial, por las víctimas del delito, olvidadas y maltratadas en desarrollo del proceso penal tradicional" 53 . Se ejerce el control social a través del consejo de conciliación y justicia compuesto por cuatro concejeros y el mismo dirigido por el vicegobernador, a los miembros se les requiere de que sean reconocidos como personas honorables, que conozcan la comunidad dotados de experiencia siendo lideres al momento de resolver problemas con un ingrediente especial el que se señala por estos el cual es el de poseer buen equilibrio en la comunidad.

\section{CONCLUSIÓN}

Dentro de la estructura de justicia Embera la segunda autoridad que nosotros calificaríamos en nuestro gobierno como orgánico del poder ejecutivo, es el que participa activa y directamente en todo proceso como autoridad judicial pues es su vicegobernador quien conforma y dirige el consejo de conciliación y justicia lo que a luces de la Constitución del 91 y traducido lo entenderíamos como el vicepresidente, es así entonces que emerge sin lugar a dudas

52 MÁRQUEZ CÁRDENAS, Álvaro E. "Normatividad y características de la Justicia Restaurativa en el contexto Nacional y su comparación en la legislación extranjera". En: Revista Prolegómenos- Derechos y Valores. No. 25. Centro de Investigaciones Socio Jurídicas. Universidad Militar Nueva Granada. Facultad de Derecho. Enero-Junio de 2010. Bogotá. p. 255.

$53 \quad$ Ibíd. p. 273. un derecho consuetudinario y que justifica su estructura de gobierno guardando relación con lo preceptuado por el Artículo 246 Constitucional.

En el sistema penal acusatorio que rige en la actualidad en territorio Colombiano, existe la participación de un sujeto procesal cuya función es de gran talante pues le asiste la de velar por el respeto de las garantías procesales aplicadas al individuo que es procesado, esto para garantizar un debido proceso a fin de una transparencia judicial. En la comunidad de Cristianía de Jardín se observa como la asamblea ponen castigos que producen polémica dentro de su comunidad, pero a la vez justifican el desarrollo de su actividad asimilándose a una rendición de cuentas o a una motivación de sus decisiones; el sistema acusatorio regulado en la Ley 906 aparte de estar inspirado en una justicia restaurativa y premiar consignó la esencia de oralidad en el procedimiento en esta comunidad, por no mencionar otras. Se observa un procedimiento verbal aunque se deja consignado un registro del caso en forma breve en un escrito con los datos principales de las partes del involucradas en el conflicto que a su vez las declaraciones e interrogatorios deben ser realizados por la mayoría de los que conforman el consejo toda vez que la presencia de todos ayudaría al momento de retomar el caso en un futuro.

La jurisdicción especial indígena es la manifestación de la autonomía jurídica y política que se le reconoce a las comunidades indígenas el ejercicio de esta jurisdicción no está condicionada ni se puede condicionar a una ley que la habilite es decir no es requisito esencial que exista una ley de coordinación entre los dos sistemas.

\section{BIBLIOGRAFÍA}

ARIEL SÁNCHEZ, Carlos. "La administración de justicia en Colombia, Siglo XX Desde la Constitución de 1886 a la Carta Política de 
1991". En: Revista Credencial Historia. No. 136. Bogotá. 2000.

Audiencia y Cancillería Real de Santafé en el Nuevo Reino de Granada. Disponible en: http://www.alcaldiabogota.gov.co/sisjur/ normas/Norma1.jsp?i=13661

BLANCO BLANCO, Jacqueline. "Colombia multicultural Historia del derecho a la Inclusión, informe Final de la investigación". En: Revista Diálogos de Saberes. No 22. Centro de Investigaciones Socio Jurídicas. Universidad Libre. Facultad de Derecho. Enero - Junio de 2005. Bogotá. p. 11.

\section{CONSTITUCIÓN POLÍTICA DE COLOM- BIA 1991.}

GUNTHER, Jakobs. Dogmática de derecho penal y la configuración normativa de la sociedad. Thomson. Civitas. Madrid. 2004.

GUZMÁN HARTMANN, Erika. Legislación Penal Indigena desde la colonia hasta 1980: ¿Imputabilidad o Inimputabilidad? Disponible en:_http:// elcentro.uniandes.edu.co/cr/antropologia/ eguzman/imputabilidad/imputabilidad.htm

HERRÁN PINZÓN, Omar. "Las Minorías étnicas Colombianas en la Constitución política del 91". En: Revista Prolegómenos Derechos y Valores. No 24. Centro de Investigaciones Socio Jurídicas. Universidad Militar Nueva Granada. Facultad de Derecho. Julio - Diciembre de 2009. Bogotá.

MÁRQUEZ CÁRDENAS, Álvaro E. "Normatividad y características de la Justicia Restaurativa en el contexto Nacional y su comparación en la legislación extranjera". En: Revista Prolegómenos- Derechos y Valores. No. 25. Centro de Investigaciones Socio Jurídicas. Universidad Militar Nueva Granada. Facultad de Derecho. Enero-Junio de 2010. Bogotá.

QUINTANA, Oscar. La filosofia politica y las falacias de la Constitución. Disponible en: www. espaciocritico.com

\section{LEY 89 DE 1980}

MEJIA QUINTANA, Oscar. Elites, eticidades y Constitución. Disponible en: http://bibliotecavirtual.clacso.org.ar/ar/libros/grupos/ hoyos/17Quintana.pdf

RESGUARDO INDÍGENA EMBERA CHAMI DE CRISTIANÍA (KAMATA RUA). La Constituyente Embera y la Jurisdicción Indigena. Jardin, Antioquia. 2001.

TAYLOR, Charles. El multiculturalismo y la politica del reconocimiento. Fondo de Cultura Económica. México. 1993.

TASCÓN GONZÁLEZ, Guillermo Antonio. Politica Organizativa de los Pueblos Indígenas de Antioquia. Volver a Recorrer el Camino. Disponible en: http://www.oia.org.co/elementos/ nuestra-politica/POL_TICA_ORGANIZATIVA_OIA_.doc.

TRAMA Y URDIMBRE. Consecuencias y disonancias entre la Justicia de los Pueblos Indígenas y el Sistema Judicial Colombiano. USAID. Valledupar

VALENCIA G, María del Pilar. Justicia embera, identidad y cambio cultural. Reflexiones en torno a una experiencia. Pág. 122. Disponible en: http://ilsa.org.co:81/biblioteca/dwnlds/od/ elotrdr026-27/elotrdr026-27-05.pdf

ZALABATA TORRES, Rubiel. Justicia Propia entre los Arhuacos. USAID. Valledupar. 2008.

\section{JURISPRUDENCIA}

CORTE CONSTITUCIONAL. Sentencia C370/02 M. P. Eduardo Montealegre Lynett.

Sentencia C-139/96 M. P. Carlos Gaviria Díaz.

Sentencia C-104/95 M. P. Hernando Herrera Vergara.

Sentencia C-394/95 M. P. Vladimiro Naranjo Mesa.

Sentencia C-377/94 M.P Jorge Arango Mejía. 
Sentencia C-027/93 M. P. Simón

Rodríguez Rodríguez.

Sentencia SU-510/98 M. P Eduardo

Cifuentes Muñoz.

Sentencia SU-039/97 M. P Antonio

Barrera Carbonell.

Sentencia T-009/07 M. P. Manuel

José Cepeda Espinosa.

Sentencia T- 048/02 M. P. Álvaro Tafur Galvis.

Sentencia T- 239/02 M. P. Alfredo Beltrán Sierra.

Sentencia T- 728/02 M.P. Jaime Córdoba Triviño.
Sentencia T- 606/01 M. P. Marco

Gerardo Monroy Cabra.

Gaviria Díaz.

Sentencia T-349/96 M. P Carlos Sentencia T- 496/96 M. P. Carlos Gaviria Díaz.

Sentencia T- 058/94 M. P. Alejandro Martínez Caballero.

Sentencia T-254/94 M. P Eduardo Cifuentes Muñoz,

Sentencia T- 384/94 M. P. Carlos Gaviria Díaz.

GACETA CONSTITUCIONAL. Número 18. Bogotá. Viernes 8 de Marzo de 1991. 